\title{
Teaching models and local-area networks
}

\author{
Tom Jones* and Brant Parker** \\ * Department of Educational Psychology, University of Calgary, Canada \\ ${ }^{*}$ Rocky View School District, Canada
}

\begin{abstract}
The thesis of this paper is that new advances in both microtechnology and LAN technology can now provide teachers with flexible and exciting instructional tools which allow for a powerful integration of teaching model, curriculum content and technology. The first section describes some of the current applications of school-based LANs. The second section discusses various teaching models, and describes an in-depth example of how a teacher may go about providing instruction by combining a LAN and these models. The third section addresses the feasibility of such an instructional approach.
\end{abstract}

\section{Introduction}

The introduction and integration of school-based local-area network (LAN) technology is increasing annually. Teachers and administrators who support LANs cite economics, more efficient and effective use of computer resources, easier management of software and overall ease-of-use as some of the major advantages (Reinhold 1989). However (and unfortunately), the use of networked microcomputers in schools continues to reflect a 'one-station, one-user' approach, especially when viewed from the perspective of the integration of teaching models and technology. That is, a LAN is for the most part considered to be a system of connected, single-CPUs that have access to shared resources rather than a powerful platform that can attend to individual learning styles and abilities and preferred teaching models and accompanying strategies. Recent advances in operating system functionality have opened the door to a potentially innovative and exciting melding of teaching models and network technology.

\section{Current applications of school-based LANs}

Presently, most school-based LANs facilitate what would normally be done on a stand-alone computer (Vernot 1989; Reinhold 1989). For example, after working through the procedure to gain access to the network (logging on), students proceed to carry out some task such as using an application program (word processor, database program), programming, using electronic mail or account housekeeping. 
Although these LAN-related activities in schools are primarily single-user in nature, some very innovative instruction has resulted. Thrush and Hardisty (1988) describe how LANs can facilitate the writing process by providing the writer with access to centralized databases, common files and other users. With respect to the teaching of writing, Thrush and Hardisty provide many practical suggestions for teachers and students. These include having a specific file which contains ideas for writing topics. This file can be browsed or added to by any student. They also propose a system of allowing copies of student composition files to be posted and to be read and electronically commented on by others. Another suggestion involves the writing of 'shared' stories by having students write collaboratively in small groups on the same topic or in the same style (narrative, expository).

Electronic forums have also been successfully used to enhance user communication on a LAN. These forums are topical message areas available to any user where students can read and respond to the comments of others. The advantage of this type of interaction is that each participant has the same access and limitations that other users have. This equality is not as easily attainable in other situations. The electronic environment removes any biases that might influence involvement in oral discussions and provides even the most reticent student with the same opportunity for participation. Bump (1990) found that students who were able to participate in what he termed Computer-Assisted Class Discussion preferred this to face-toface interaction. Furthermore, Bump found that synchronous communication (users communicating online simultaneously) was preferred by regular LAN users to asynchronous communication (for example, electronic mail). However, his research also indicates that there may be a tendency for students to write messages on the computer that are more direct and pointed than would be the norm in ordinary conversation, and that this can often result in a confrontational style.

LANs have also been used to provide for more specific and guided user activities. For example, one school in Southem California uses a LAN, authoring software and a library database to facilitate the writing of research reports and papers (Dezell 1991). Via a Hypercard stack and an online library database, students are guided through the steps of formulating research questions, making an outline, locating library resources that relate to the topic, and determining whether or not these materials are currently available from the library.

Skor (1988) discusses a scenario in which a LAN is used as an integral part of a grade 11 Physics programme. Information about class topics and daily assignments are posted for students. Answering of preliminary lab questions is completed on the LAN using a word processor which may take several days but which can be done from a variety of locations within the school. A spreadsheet program is used to collect the data and perform necessary calculations, and the word processor is used again to compose the lab report. Additional information is available to the students through the use of an extensive physics database. The end product is submitted electronically to the instructor and the results are returned to the students in the same manner.

Having recognized the proliferation of LANs in schools, network products are being marketed specifically for use in school settings in order to make the maintenance and operation of a network less troublesome. One such product, IBM's ICLAS (IBM Classroom LAN Administration System), provides a network interface which allows for five levels of users: generic users, students, teachers, a network administrator and a system operator. With ICLAS, a teacher can quickly and easily provide a student or a group of students access rights to certain applications or files and allow them to have read/write privileges to selected directories on the 
file server. Thus a teacher can place students into groups or classes and create user menus which list applications that are available to each group. The teacher can optionally create a student directory on the server which will become the default location where files will be saved, or assign the workstation's local drive as the default. In addition, ICLAS will also permit teachers to control whether or not students are able to send messages and interact in real time with other students and/or teachers who are using the network, or to any other user via electronic mail. Products like ICLAS go a long way to making a network an attractive teaching resource.

In the near future, local-area and wide-area networking technology (LAN, WAN) will give students access to information that might be located in the same room (for example, common datafiles), in the same building (for example, network CD-ROM) or even in other countries. Because the communication infrastructure provided by networking technology rapidly handles the transfer of data, there exists great potential for interactivity between the classroom and the information source.

With emerging standards in layered networking protocols (for example, the Integrated Services Digital Network (ISDN)), teachers will be able to provide students with access to information in a variety of formats: text, graphics, digitized and compressed video, and digitized sound (Madron 1990). The information source may be a centralized database (for example, CD ROM), shared datafiles, synchronous communication between users (electronic conferencing), asynchronous communication (electronic mail), or remote access to online information systems. Indeed, future wide-area networks will allow for students to collect information on a topic by accessing simultaneously various information sources - both local and global on the network. This could be made possible by means of a software 'gopher' which would use student-defined keywords, graphical cues, or other information discriminators to search systematically each source for the specified information. In this way, students could retrieve information from a number of external sources.

However, even with these software and hardware advances, the power and functionality of LANs have been primarily used to provide supplemental support for teachers and students. That is, the use of LANs in educational settings has resembled more a business model than a model that reflects a consideration of teaching models and the concomitant strategies.

Although the advances in centralized and distributed computing have been remarkable, they have yet to be exploited in a manner that will allow teachers to teach some curricular content in a particular manner for a particular group of students - that is, match a teaching model with the individual characteristics of the learner. Traditional educational software (CAI, drill and practice programs, simulations, educational games) have not been designed to accommodate different teaching styles for the most part, but rather to be used by the individual learner or by a teacher who can creatively work the software into the overall instructional program. This can be effective but it is rather like putting the cart before the horse.

On a broader scale, many educators have concluded that computers do not necessarily provide the enhancements to learning that were promised in the early 1980s (Skor 1988), although it should be pointed out that there has been some success (Roblyer 1988). Rather, a decade of experience has shown that the educational benefits of computers have resulted from the manner in which the technology has been applied by teachers and students (Knapp 1989; Collins 1991). Educators have concluded that the more closely the application of the technology complements the teaching and learning styles, the greater the impact on learning (Migliorelli 1987; Tesler 1991). 
Figure 1: Integration of teaching models and technology

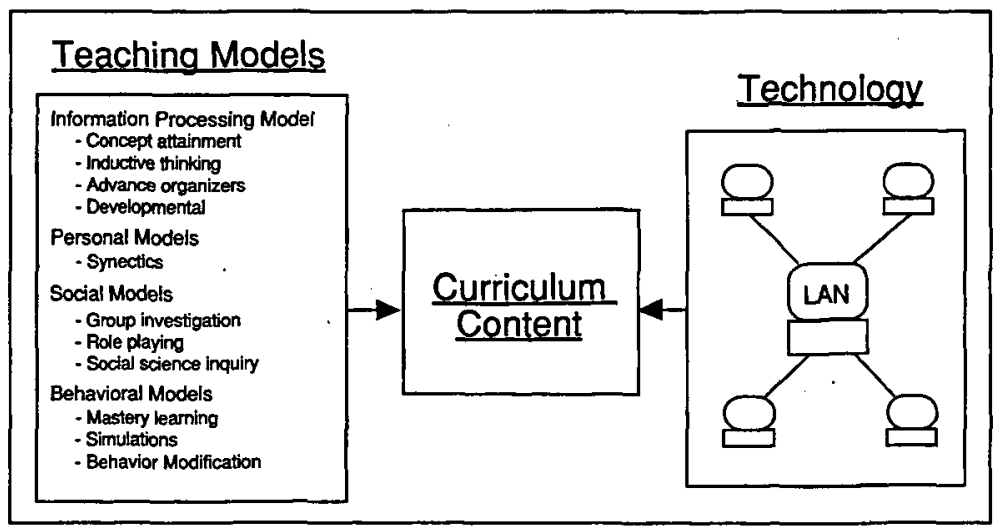

What is needed, then, is a different approach to the use of technology in schools, one which attends first to the teaching model that the teacher wishes to employ for a certain instructional unit or event, and one which also can be adapted to the different abilities and interests of the learner. Interestingly, the latest advances in LAN technology can now support the demands that would be placed on a school-based LAN if the approach delineated above and fleshed-out below were to be implemented. Teaching and learning that is supported by technology not adapted to technology is now possible.

\section{Teaching models and LANs}

If the previous attempts to integrate technology into the curriculum have been only partially successful, what approach should be taken and what role do local-area networks play? One answer is to start from the pedagogical viewpoint (that is, teaching and learning), and then to determine how a LAN might provide a powerful resource in which teachers and students will be able to carry out activities which are not possible in a LAN-less classroom. In their seminal book, Joyce and Weil (1986) discuss 20 approaches to teaching and learning and the underlying theories. These models describe approaches that range from didactic to constructivistic, from structured to non-structured, and from teacher-directed to student-directed. Joyce and Weil group these approaches into four broad categories or 'families of models': information processing models, personal models, social models, and behavioural systems models.

A close look at each model within the four families reveals that not all readily lend themselves to a match with instructional technology (see Joyce and Weil for details). The models that do, however, are presented in Figure 1, and a short description of each model's main thesis is given in Appendix A. The point is that this innovative approach will address the bringing together of three factors: the teaching model, the curricular content and a local-area network.

What teacher would not like to have the option of planning a unit on a topic (for example, trial balance) and have at his or her fingertips a means by which the instruction could be made to reflect an appropriate teaching model listed in Figure 1? For instance, one teacher might prefer to have the students first achieve fluency (mastery learning) in the terms which describe the report (assets, liabilities, equity, etc.), then move on to a presentation (advance organizers) of sample trial balances, and finally to run a simulation of a small business in which the goal is to come up with a trial balance (simulations). 
This could well be followed by some activities on the part of the students, and followed up with a brainstorming session on how to prepare a trial balance for easy comprehension (synectics). Underlying these activities might be a desire on the part of the teacher to ensure that no one student is left out and that some remediation can be provided to a certain number of students who are not able to carry the necessary operations at a rate commensurate with the other students (behaviour modification). Anóther teacher might wish to provide instruction on the trial balance by presenting the students with the results of a series of journal entries, and then leading them toward the concept (and its concrete counterpart) of a summary statement (inductive thinking and concept attainment).

Numerous examples could be generated along these lines, but the question would remain about the feasibility of being able to teach some content using one or a number of these models. Are teachers able to do this now? The answer is perhaps: a little, but not as much as they would like, and it would definitely take a great deal of time and effort even if it were possible. One solution is to structure the curricular content and its subsequent delivery in a way that it lends itself (at least to a large extent) to being run on a classroom-based LAN. Inherent in this is the necessity to re-fashion the subject matter so that it can be moved to an electronic medium. This is no small concern, but it should also be noted that use of a LAN as an integral if not central component in a course of studies will also open up the classroom to other sources of information (see above), and these other sources can provide unique opportunities for the teacher and students.

At the core of an implementation along these lines is a recognition that the traditional manner in which a curriculum is developed must change. In particular, after decisions have been made about goals and learning objectives, a great deal of attention will have to be paid to how various topics will be treated vis-a-vis the teaching models. For example, if it is decided that the overall model will provide for a group investigation, then the options for dividing the

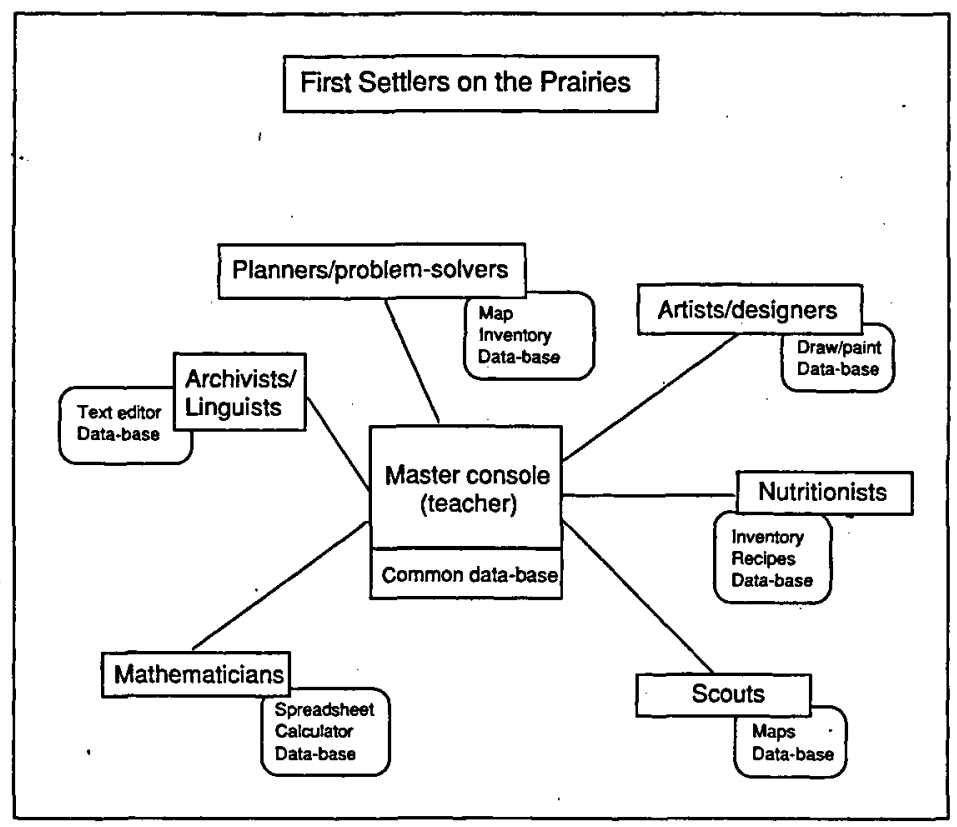

Figure 2: Group learning example 
students into groups must be pre-determined. Also the nature of the tools that will be available to each group will also have to be commensurate with that group's contribution. In any event, the driver for these types of decisions when developing the curriculum will be the content itself. The ideal, of course, would be a curricular structure which would allow for a maximal crossing of the teaching models and the course topics.

\section{Example}

To provide a classroom-based example of how these ideas might be implemented, imagine a typical (North American) grade 7 class (teacher and students) who are beginning a unit on the settling of the prairies. Without going into detail about how this event took place, let us take a look at how a teacher who is teaching this unit and who has decided on a 'group investigation' model might take advantage of a LAN.

\section{Set-up}

The LAN would initially be configured by assigning students to groups (Figure 2). As part of the unit set-up, the teacher could allocate the stations in such a manner as to match the groups' tasks and tools with the strengths of each of the students. In this example, there might be provision for a maximum of six groups (planners/problem solvers, archivists/linguists, mathematicians, scouts, cooks and designers/engineers).

The teacher may decide that all six groups should be used, and that the 30 or so students in his or her classroom can be appropriately placed. This calls for an in-depth knowledge of a . number of factors which impact on learning - past achievement, level of mastery in required areas, group dynamics, motivation, preferences - and a detailed profile of how the students fare on these factors. In other words, the membership of the groups (and note that not all six have to be assigned) is controlled directly by the teacher and should result in the most effective matching of required skill and student expertise.

\section{Group tools}

Once the make-up of the groups has been determined, each group would be given access to that group's tools - that is, the programs they will be using (Figure 3). The planners/problemsolvers would be supplied with information about the ultimate goal of the unit (for example, settling in some western locale), an overall inventory of the group's resources, a decisionmaking program and an updated database. The archivists/linguists would be responsible for maintaining an accurate record of the pioneers' day-to-day efforts, for interpreting the records of previous explorers and for the translation and interpretation of communications between the settlers and the natives.

This group would have access to a text editor, a separate database or compendium of earlier explorers' records, and a visual database of native ideographic writings. The mathematicians, as might be expected, would carry out the necessary calculations required by any of the other groups. Their tools would be a calculator and spreadsheet-like software which would provide for what-if? questions. The scouts would have at their disposal maps of varying degrees of accuracy and completeness. The nutritionists would be charged with the acquisition, preparation and preservation of food. The designers/engineers would be required to design (and to modify, if necessary) the means of transportation, and to design and build temporary structures (huts, bridges, rafts). 
Inter-group communication

A unique and very powerful feature of establishing groups as described above is that although each group will have its unique tools, responsibilities and activities, all the groups will have to interact in order to acquire pertinent information for their own activities and decisionmaking. For example, the planners/problem solvers will have to maintain close contact with the scouts when the settlers are about to break camp and enter unknown territory. The information they will need may be visual (a first-time map of a region), textual (written descriptions of up-coming terrain or obstacles) and perhaps auditory (sound of waterfalls/rapids). They will also require updates from each of the other groups and will either request them or acknowledge them when they are available. The mathematicians in this instance might be giving assistance to a number of the other groups. Based on what information the scouts have provided to the planners/problem solvers, this group could be asked by the designers to work out the number of days it will take for the settlers to reach a particular destination. The cooks, after having decided on what food will be available, might request the mathematicians to determine how much fuel will be required in order to prepare the food. The archivists/ linguists might query the scouts about the natives who were encountered in order to determine which native language will be used for communication.

Note that the results of each group's decisions, calculations or designs would have an immediate effect on the central database (and updated on each group's screen), and would be accessible by each group as input for further group activities. Note also that the information shared among groups may be textual, visual (still frame or full-motion video) and auditory.

\section{Teaching models}

During all this activity, the teacher would have a great deal of control over what transpires. In particular, the teacher would be able to alter instructional events, based on the teaching models described above, with each of the groups so that the members might acquire the learning objectives of the curriculum while contributing to the unit goal - that is, moving the settlers westward. Thus, the teacher might be aware that the scouts are lacking the concept of a map legend and the skill of interpreting various markings. This group would then be presented with information on legends (concept attainment), given opportunities to demonstrate mastery of these concepts (mastery learning), and perhaps individual members of the group would be required to work a while longer until mastery is achieved (behaviour modification). For another group, the mathematicians, it may arise that they need certain formulae (for example, rate $\mathrm{x}$ distance) in order to compute distances to be travelled. The teacher in this instance might apply an inductive thinking model by presenting to the group a number of examples which call for predicting a final answer. The examples could include data which has to be generated by the group.

What is being argued for here is the ability for a teacher to control how content is delivered (in other words, which model) to each group based on that group's learning characteristics. Realistically, not all models will be covered for each instructional event; the onus will be on the curriculum designers to decide which sub-topics of the content lend themselves to which model, and which of these sub-topics are amenable to being developed for a LAN. It should also be emphasized that if the type of system being described were to be implemented, it does not preclude the introduction of offline activities. In fact, designing a curriculum with no provision for such activities would restrict a teacher's options and would not be recommended. 
Figure 3: Group tools

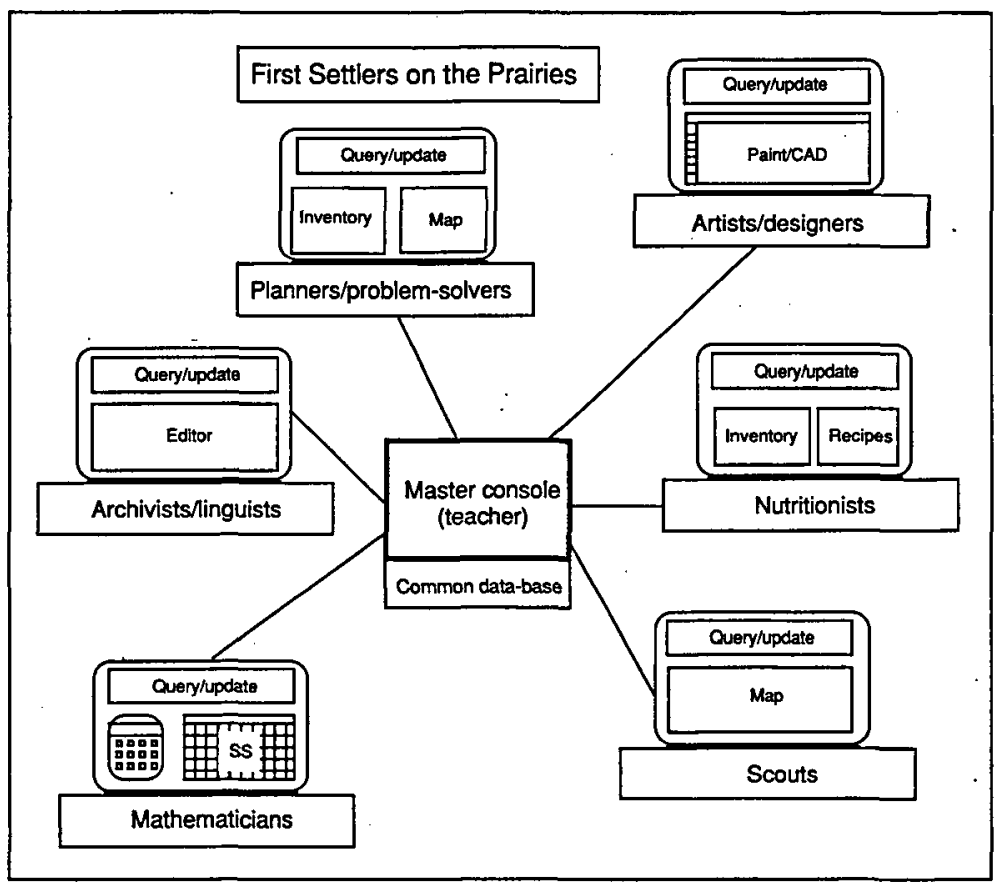

\section{Implementation}

Is it possible to implement these ideas given the state of today's technology? It appears so. What is required is a peer-to-peer network which includes a single file-, print- and communications-server (preferably with a fast CPU and, more importantly, fast disk access) and a number of clients (emphasis on the mastery leaming model would call for more stations than emphasis on the group investigation model). The server, over and above providing for access to shared resources - printers, CD-ROM, modems, video sources - , will also turn full duty as a database server given that all clients (workstations) will be reading and writing to a common database (Figures 2 and 3) which will provide the teacher and all students with a 'latest' version of their progress. Because individual clients will possibly need to multitask, a good choice for network software would be either Novell's Netware or 3Com's LAN Manager running over OS/2. None of these are suggestions that reflect low-end computing (and the matter of client software has not yet been addressed), but it will be obvious that what has been outlined in this paper calls for a major revamping of how instruction and technology are integrated.

\section{Summary}

The object of this paper has been to consider an approach for the integration of (a) various commonly-held approaches to teaching (models) with (b) a sophisticated, computer-based resource as the vehicle for delivery. The rationale for such a plan has been to provide teachers and learners with an effective, powerful and flexible tool for both instruction and learning. Can it be implemented? We believe so, given that LAN technology has matured to the point where such a resource could be developed. Does it put the horse (pedagogy) before the cart (technology)? We think so. 


\section{Appendix A: Teaching Models}

\section{Information-processing models}

The information processing family of models encompasses those which are primarily concerned with the acquisition of new knowledge, testing of this knowledge, collecting and organizing data, and/or developing an awareness and understanding of problems and arriving at solutions. The central tenets of these models are as follows:

- concept attainment: an effective method for organizing information and for learning concepts;

- inductive thinking: how to find and organize information and creating and testing hypotheses;

- advance organizers: provides a cognitive structure for comprehending material;

- developmental model: the goal is to match instruction with the learner's level of cognitive ability.

\section{Personal models of teaching}

Models grouped into the personal family are those which revolve around the individual and his or her experiences. The emphasis in these models is on the perspective and knowledge a person acquires through his or her own actions and interactions with others. Unlike their information processing counterparts, the main goal of these models is not to improve individuals' cognitive skill which assists them in acquiring new information. Rather, personal approaches aim at improving the individual learner's self-concept, confidence, effectiveness, while helping the individual construct his or her own understanding and knowledge. They challenge individuals to assume responsibility for their own learning and to extend the limits of their own understanding.

Synectics: teaches collaborative problem-solving to result in new, creative perspectives.

\section{Social models of teaching}

The social family of models consists of those which are primarily based on group work and social interaction. That is, the models operate on the social processes found in group and collaborative learning environments. These co-operative settings, and the group dynamics that are prevalent within them, provide a means by which social growth is fostered and new knowledge, skills, and shared or negotiated understandings are acquired.

Group investigation: application of the principles of the democratic process to encourage group members to construct new knowledge;

Role playing: situations are presented to students who act out a problematic situation and then analyse it;

Social science inquiry: defining a problem, testing hypotheses, gathering data and making generalizations. .

\section{Behavioural systems models of teaching}

The behavioural systems models are built on the premise that learning can occur through feedback received in response to one's actions. The approaches are largely founded on the work of classical conditioning theorists, and are based on a stimulus-response-reinforcement 
model. In these approaches, large tasks are broken down into smaller behaviours. The feedback provided to the leamer is the primary means by which observable behaviours are either repeated or modified.

Mastery learning: individualized learning of highly stratified skills and concepts;

Simulations: principles of cybernetics are applied to learning environments;

Behaviour modification: leaming occurs as a result of the manipulation of the environment.

\section{References}

Bump, J. (1990), 'Radical changes in class discussion using networked computers', Computers and the Humanities, 24, 1-2, 49-65.

Collins, A. (1991), 'The role of the computer technology in restructuring schools', Phi Delta Kappan, 34, 9, 28-36.

Dezell, J. (1991), 'The impact of networking on education', Curriculum Product News, February, 2-3.

Joyce, B. and Weil, M. (1986), Models of Teaching, London, Prentice-Hall.

Knapp, L. (1989), 'Classroom networks: today and tomorrow', Apple Classroom of Tomorrow, Report 5, Cupertino CA, Apple Computers.

Madron, T. (1990), Local Area Networks: The Next Generation, New York, John Wiley.

Migliorelli, F.A. (1987), 'Microcomputers and teaching styles: creative applications and integration of commercial courseware', paper presented at the Adult Education and Technology Conference, Pittsbürgh PA.

Reinhold, F. (1989), 'Educators explore the lay of the LAN', Electronic Learning, 8, 5, 34-37.

Roblyer (1988), 'The effectiveness of microcomputers in education: a review of the research from 1980-1987', T.H.E. Journal, September, 85-89.

Skor, R. (1988), 'The educational importance of local area networks in secondary schools', Computers in Education, 13, 2, 129-134.

Tesler, L. (1991), 'Networked computing in the 1990s', Scientific American, 265, 3, 86-93.

Thrush, E. and Hardisty, D. (1989), 'Computer networks for language learning: the creation of meaning through interaction', ERIC Document 325668.

Vernot, D. (1989), 'Get the whole story before you plug into a computer network', The Executive Educator, 11, 3, 21-23. 